\title{
MAPEAMENTO GEOAMBIENTAL DE SÃO VICENTE DO SUL - RS
}

\author{
Gabriel de Mamann Nascimento ${ }^{(a)}$, Vinicius Silveira dos Santos ${ }^{(b)}$, Daniel Junges Menezes ${ }^{(c)}$ \\ (a) Professor de Geografia, Colégio G10 (Santa Maria - RS), gabriel_._nascimento@hotmail.com \\ (b) Geociências/Pós Graduação em Geografia, Universidade Federal de Santa Maria, \\ viniciusgeografia93@gmail.com \\ ${ }^{(c)}$ Geociências/Pós Graduação em Geografia, Universidade Federal de Santa Maria, danieljunges@hotmail.com
}

\section{Eixo: GEOTECNOLOGIAS E MODELAGEM ESPACIAL EM GEOGRAFIA FÍSICA}

\section{RESUMO}

\begin{abstract}
Através do viés que os estudos geoambientais nos proporcionam, o presente trabalho objetiva a realização do mapeamento geoambiental do município de São Vicente do Sul/RS, localizado no oeste do Rio Grande do Sul. Com a inter-relação de parâmetros do meio físico, como hidrografia, atributos do relevo, solos, litologia e uso e ocupação da terra, foi possível a compartimentação da área de estudo em sistemas geoambientais: Sistema São Vicente, Sistema de Colinas em Arenito, Sistema das áreas Planas do Jaguari e Ibicuí e Sistema dos morros e morrotes isolados. Cada sistema apresenta restrições e aptidões ambientais de acordo com suas caraterísticas. A definição desses sistemas é fundamental no auxílio no planejamento e ordenamento territorial do município.
\end{abstract}

Palavras chave: Sistemas Geoambientais. Mapeamento. São Vicente do Sul/RS.

\section{Introdução}

Os estudos geoambientais vem se destacando nas últimas décadas, sobretudo no âmbito da geografia enquanto ciência, pois propiciam discussões atreladas a integração de informações do meio físico frente à presença antrópica assim como seus meios de uso do espaço. Ainda nesse viés, os estudos geoambientais acarretam em um norteamento de alternativas para determinada área, possibilitando a realização de zoneamentos que indicam restrições a aptidões ambientais. Friori (2004) destaca que o objetivo dos mapeamentos geoambientais consiste na compartimentação do território com base nas características do geoambiente, suas inter-relações e relações com o meio biológico e com as atividades antrópicas, colocando em evidência as potencialidades e restrições de uso. Nessa perspectiva Robaina et al (2005) afirmam que o processo de mapeamento geoambiental tem como rotina fundamental a divisão da área em unidades, de acordo com a variação de seus parâmetros. $\mathrm{O}$ trabalho consiste em definir sistemas geoambientais do município de São Vicente do Sul/RS, localizado na porção centro-oeste do Estado do Rio Grande do Sul (Figura 1). Este possui uma área total de $3.147,631 \mathrm{~km}^{2}$, uma população total estimada em 23.555 habitantes, bem como, uma densidade demográfica de aproximadamente $7,31 \mathrm{hab} / \mathrm{km}^{2}$ (IBGE, 2010). 


\section{OS DESAFIOS DA GEOGRAFIA FÍSICA NA FRONTEIRA DO CONHECIMENTO \\ Instituto de Geociências - Unicamp \\ Campinas - SP \\ 28 de Junho à 02 de Julho de 2017}

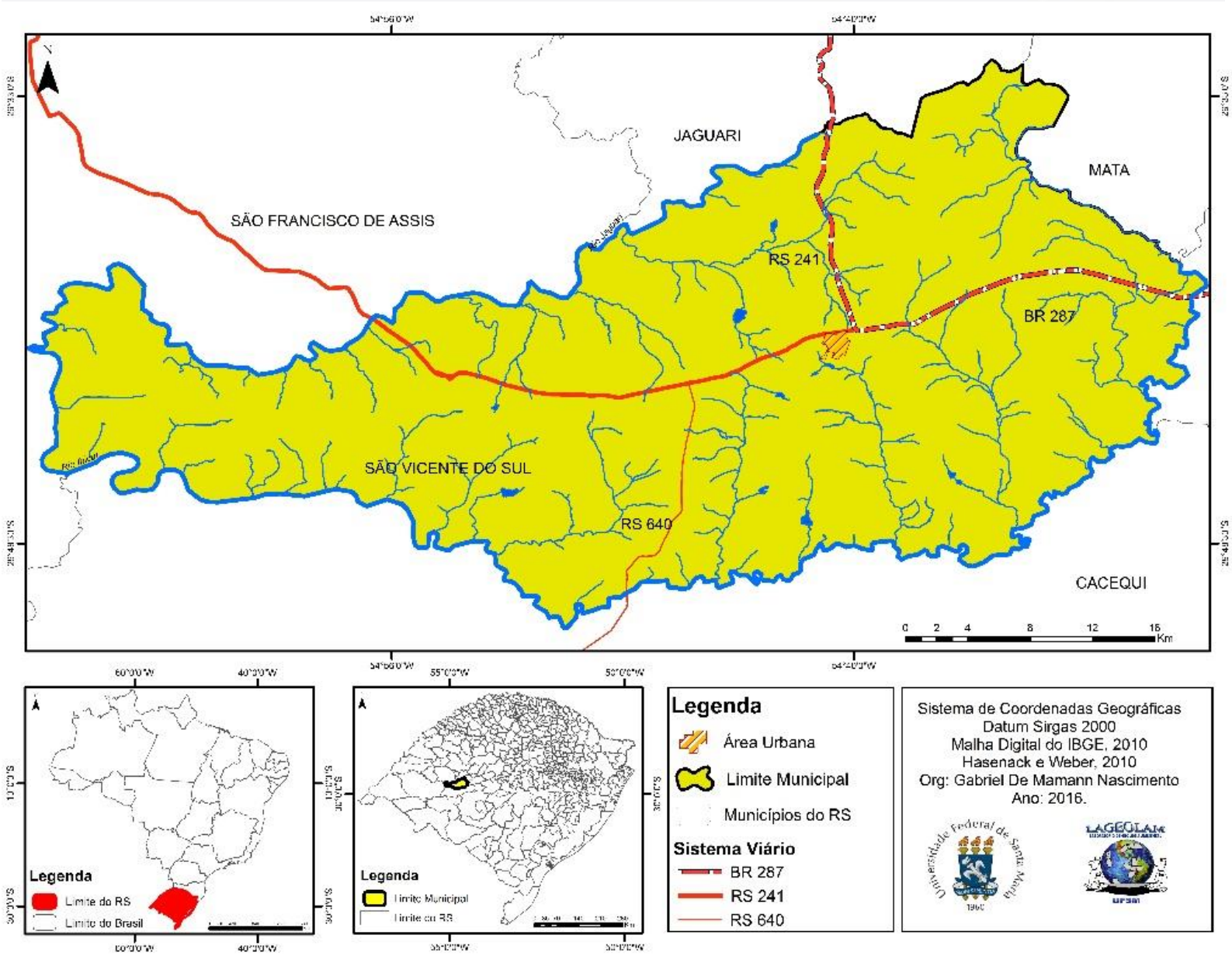

Figura 1 - Localização de São Vicente do Sul

A escolha pela área de estudo, se dá pelo fato de o município ser unidade territorial que é administrativamente planejada, e diante disso, possibilitando a aplicabilidade da pesquisa, ainda assim destaca-se a ocorrência dos dois principais rios do oeste gaúcho: Rio Jaguari e Rio Ibicuí, delimitando o terrítório do município e salientando a ocorrência de uma sgnificativa área inter-fluvial (figura 2).

Os elementos analisados para a realização do mapeamento geoambiental foram: hidrografia, unidades de relevo, litologia, solos, uso e ocupação da terra. A partir da inter-relação desses fatores possibilitouse o mapeamento geoambiental de São Vicente do Sul, esse que foi dividido em unidades que determinam aptidões e restrições ambientais de cada recorte espacial. 

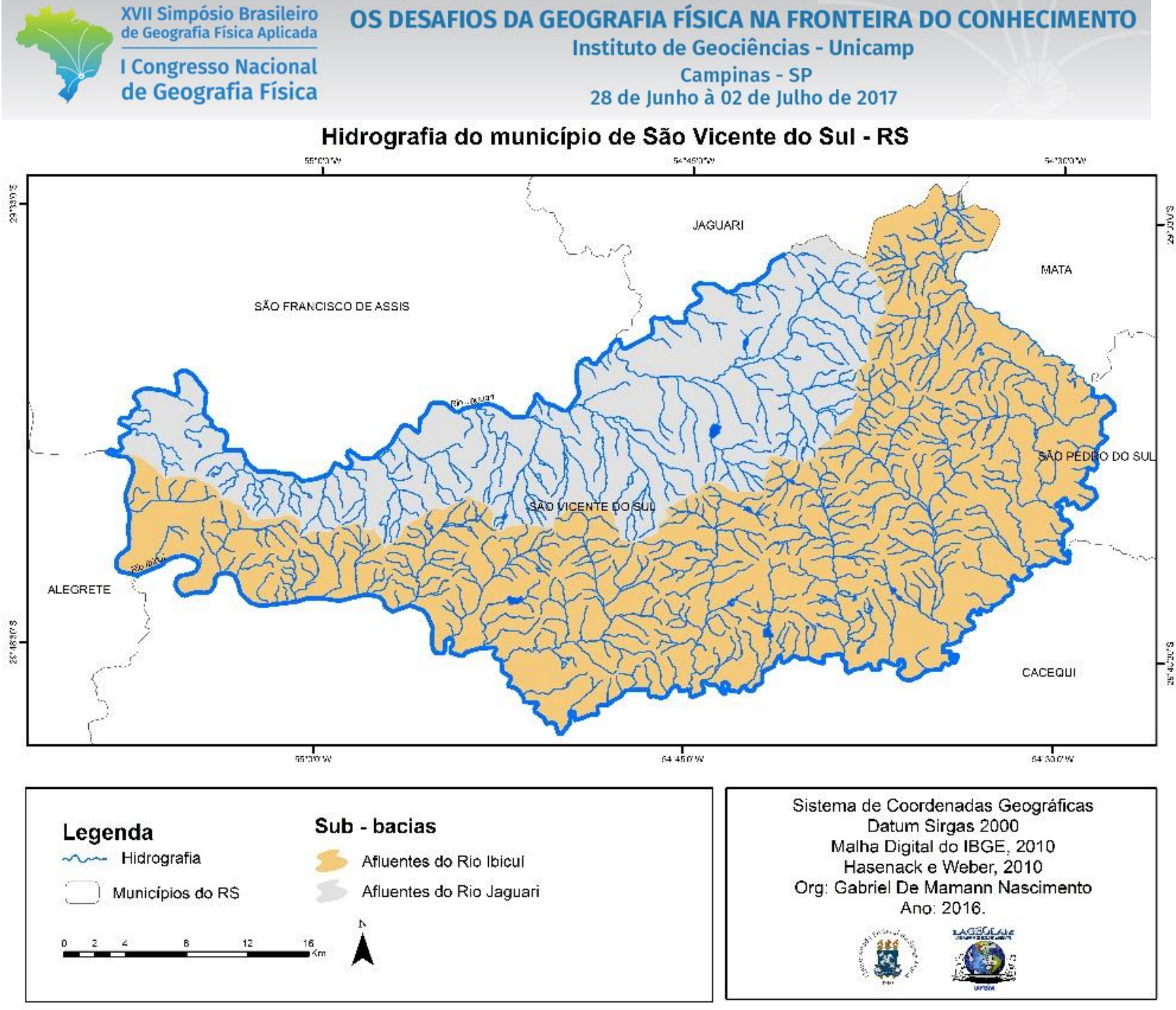

Figura 2: Área interfluvial de São Vicente do Sul - RS

\section{Procedimentos metodológicos}

O trabalho dividiu-se em três etapas: Levantamento bibliográfico e cartográfico, elaboração dos mapas temáticos e por fim o mapeamento geoambiental. O levantamento bibligráfico denota a etapa em que se estabelece os pressupostos teóricos-metodologicos norteadores para a elaboração da pesquisa, embasada na cartografia geoambiental, assim como propostas de realização de mapeamentos da natureza geoambiental. O levantamento cartográfico é realizado através da diponibilidade de dados da área de estudo, de acordo com cada parâmetro utilizado para a conclusão do mapeamento geoambiental.

A elaboração dos mapas temáticos, que corresponde a segunda etapa, deu-se através da utilização do geoprocessamento, com o uso de ferramentas do software ArcGis versão 10.1. Os mapas elaborados e seus métodos são respectivamente:

Hidrografia: Base Cartográfica Vetorial Contínua do Estado do Rio Grande do Sul, com escala 1:50.000 desenvolvida por Hasenack e Weber (2010) e a Malha Digital do IBGE (2010) também na 
escala 1:50.000: correspondem as bases cartográficas utilizadas como dados primários para a elaboração dos mapas temáticos.

Hipsometria: Para análise das hipsometrias no município, utilizou-se a imagem SRTM (Shuttle Radar Topography Mission), com resolução espacial de 30m, obtidas junto ao United States Geological Survey (USGS)1: Para a definição das classes hipsométricas, analisou-se as cotas altimétricas máxima e mínima, obtido através do histograma de frequência do software. A cota máxima apresenta o valor de 408 metros, enquanto que a cota mínima apresenta o valor de 61 metros. Assim, foram definidas 5 (cinco) classes hipsométricas: $<90 \mathrm{~m}, 90-110 \mathrm{~m}, 110-130 \mathrm{~m}, 130-150 \mathrm{~m}$ e $>150 \mathrm{~m}$.

Declividades: O mapa de declividade foi elaborado utilizando as classes proposta pelo Instituto de Pesquisas Tecnológicas (IPT), sendo: $<2 \% ; 2-5 \% ; 5-15 \%$; e $>15 \%$, através da ferramenta ArcToolbox "slope". O limite de $2 \%$ marca áreas planas em geral associadas às drenagens e sujeitas a ocorrência de inundações e os principais processos estão ligados a deposição de sedimentos; 5\% representa áreas com baixa declividade, porém alguns processos erosivos se tornam significativos; $15 \%$ marca a faixa que define o limite máximo para o emprego da mecanização da agricultura, e também delimita áreas propicias a ocorrência de processos de movimento de massa e escorregamentos.

Unidades de Relevo: Para a definição das unidades de relevo, foi utilizada a metodologia do Instituto de Pesquisas Tecnológicas IPT (1981), conforme a Tabela I. As classes definidas são: Morros Isolados, com elevações com amplitude altimétrica superior a 100 metros e declividade de encostas superior a 15\%; Colinas Fortemente Onduladas, com áreas que representam declividade entre 5 e 15\% e amplitude altimétrica inferior a 100 metros; Colinas Suavemente Onduladas, com áreas com declividade entre 2 e 5\% e amplitude inferior a 100 metros; Associação de Colinas, Morros e Morrotes - com áreas onde é possível observar colinas com declividades que variam entre 2 e 15\% com amplitude altimétrica inferior a 100 metros associadas a morros e morrotes; Áreas Planas, com declividades menores que $2 \%$.

Tabela I - Classificações dos tipos de relevo.

\begin{tabular}{ccc}
\hline AMPLITUDE & DECLIVIDADE & UNIDADE DE RELEVO \\
ALTIMÉTRICA & & Áreas Planas \\
\hline & $<\mathbf{2 \%}$ & Colinas Suaves \\
\cline { 2 - 3 }$<100$ metros & $\mathbf{2 - 5 \%}$ & Colinas de Altitude \\
\cline { 2 - 3 } & $>\mathbf{1 5 \%}$ & Morrote \\
& $>15 \%$ & Morros \\
\hline
\end{tabular}

Fonte: IPT (1981).

Litologia/Solos: A base cartográfica referente as litologias e solos estão disponíveis pela Companhia de Pesquisa de Recursos Minerais (CPRM), na escala 1:250.000, sendo conferidas com os dados encontrado em trabalhos de campo. 


\section{OS DESAFIOS DA GEOGRAFIA FÍSICA NA FRONTEIRA DO CONHECIMENTO Instituto de Geociências - Unicamp Campinas - SP \\ 28 de Junho à 02 de Julho de 2017}

Uso e Ocupação: A classificação da imagem, para a elaboração do mapa de uso e ocupação da Terra, se deu através do software Envi 5.1 e para a edição dos mapas e cálculo de área utilizou-se o software ArcGis 10.0. As imagens foram obtidas através do portal online (http://earthexplorer.usgs.gov/) do Serviço Geológico dos Estados Unidos (USGS). Na classificação das imagens utilizou-se o algoritmo Maxver (máxima verossimilhança), que é um algoritmo de classificação supervisionada, que usa parâmetros estatísticos na classificação de pixels de valores semelhantes, visando áreas homogêneas ou de mesmo valor numérico.

A última etapa do trabalho, consiste na elaboração do mapeamento geoambiental. As definições dos sistemas geoambientais seguiu a proposta metodológica desenvolvida por Trentin \& Robaina (2005). Nessa perspectiva definiu-se sistemas geoambientais, e caracterizadas as restrições e aptidões de cada unidade, para assim incluir breves e genéricas recomendações para contribuir no planejamento e ordenamento sustentável do território vicentino.

\section{Resultados alcançados}

Os resultados detém a inter-relação de parâmetros do meio físico, à medida que são caracterizados de forma individual, para que finalmente resulte no produto final, o mapeamento geoambiental de São Vicente do Sul - RS.

\section{Hidrografia}

As principais e mais relevantes drenagens de São Vicente do Sul são as do Rio Ibicuí e o Rio Jaguari, destaca-se que o divisor de águas entre as bacias hidrográficas desses rios perpassa pelo eixo latitudinal do município, como mostra a figura 2 (p.2). Dentro dessas grandes duas bacias o município tem 16 sub bacias hidrográficas destacados na figura 3, as sub-bacias são determinadas pela ordem de hierarquia segundo a classificação de Stralher (1952). Majoritariamente apresentam-se drenagens de $3^{\circ}$ ordem, com exceção dos afluentes do rio Ibicuí e Jaguarí, que confluem diretamente para os canais principais.

\section{Hipsometria}

O município de São Vicente do Sul tem como menor cota altimétrica o valor de 61 e a maior cota altimétrica corresponde a $408 \mathrm{~m}$, tendo assim uma amplitude altimétrica de $347 \mathrm{~m}$. Nessa variação de altitude estabeleceu-se 5 classes hipsométricas para a realização do mapa. A porção que teve maior ocorrência foram as áreas entre 90 e 110 metros, correspondendo a 38,33\% da área total. Essas porções se associam as drenagens que compõem as bacias do Rio Ibicuí e o Rio Jaguari dentro da área.

As áreas com altitude entre 110 e 130 metros apresentam 25,99\% do município. A classe hipsométrica que indica altitudes inferiores a 90 metros correspondem a 21,36\% da área, associadas às jusantes 


\section{OS DESAFIOS DA GEOGRAFIA FÍSICA NA FRONTEIRA DO CONHECIMENTO \\ Instituto de Geociências - Unicamp \\ Campinas - SP \\ 28 de Junho à 02 de Julho de 2017}

junto ao Rio Ibicuí e o Rio Jacuí. A classe que está entre as altitudes de 130 e 150 metros apresenta $11,57 \%$ da área total vicentina, e tem como principal relação grande parte das cabeceiras das drenagens do município.

\section{Declividade}

As áreas planas estão associadas as principais drenagens na área do município, as porções sul e sudeste com a jusante do rio que desembocam no Rio Ibicuí, áreas com declividade inferiores a 5\% predominam no limite do município, essas que possibilitam mais deposição. As áreas entre 5\% e 15\% representam a $37,55 \%$ do município que estão em sua maioria associadas a cabeceiras de drenagens. As áreas superiores a 15\% correspondem a apenas 2,26\% da área total, que estão associados a morrotes isolados. As principais drenagens da porção sul do município, que são Arroio do Salso, Arroio Cucha, Arroio dos Acostas e Arroio das pedras estão inseridos nas áreas com declividade entre 2 e 5\%. Na porção nordeste encontramos área de declividade superior a 15\%, assim como em pontos específicos, correspondentes aos morrotes isolados.

\section{Unidades de Relevo}

As colinas, principais formas na área em estudo, são constituídas por vertentes suavemente onduladas, com declividades entre 5 e 15\% e altitudes entre 100 e 140 metros. As formas de relevo atribuídas como morros isolados de topos aguçados ocorrem entre as colinas, correspondem às maiores altitudes (superiores a $200 \mathrm{~m}$ ) e declividades da área. Destacam-se o Cerro do Loreto (338 metros de altitude), Cerro do Agudo (288 metros), Cerro da Glória (278 metros) e Cerro do Belém (256 metros). As formas de relevo atribuídas como morrotes isolados de topo plano, tem altitude próxima dos 190 metros e declividade superior a 15\%, ocorrente no Cerro do Pelado. As áreas planas associam-se com as planícies de inundação dos afluentes dos Rios Ibicuí e Jacuí, com altitudes inferiores a 90 metros, onde ocorrem depósitos de sedimentos fluviais recentes.

\section{Litologia}

O município de São Vicente do Sul apresenta em sua litologia rochas sedimentares que se diferenciam por tempo e contexto de formação: Arenito eólico vermelho friável - formação Pirambóia, Arenito fluvial micáceo - formação Sanga do Cabral, Arenito fluvial com grânulos - formação Guará e as deposições recentes. Os depósitos recentes são formados por sedimentos das planícies de inundação dos afluentes do Rio Ibicuí e Jaguari. O Arenito fluvial com grânulos - formação Guará é constituída por arenitos de cores vermelho a amarelo-claro, com grânulos de sílica que estão associados à Formação Guará, essa litologia tem pequena porção na região nordeste da área. A ocorrência do arenito micáceo é proveniente da formação Sanga do Cabral, também associada a Bacia Sedimentar do 


\section{OS DESAFIOS DA GEOGRAFIA FÍSICA NA FRONTEIRA DO CONHECIMENTO \\ Instituto de Geociências - Unicamp \\ Campinas - SP \\ 28 de Junho à 02 de Julho de 2017}

Paraná. A presença de minerais do grupo das micas na fração areia fina e estratos cruzados acanalados são características que permitiram sua definição espacial. Tem maior área de ocorrência no município.

\section{Solos}

No levantamento de solos, foram identificadas as seguintes classes:

Gleissolos: são solos pouco profundos, de cor acinzentada ou preta. São constituídos de materiais inconsolidados (sedimentos ou saprólitos) e geralmente encharcados. É um tipo de solo propício a cultura do arroz, devido este ser um solo muito mal drenado e ocorrer em relevos planos.

Os Argissolos são solos geralmente profundos, de $1 \mathrm{~m}$ a 2,5m, bem drenados, ocorrendo em relevo suavemente ondulado a ondulado. Estão associados à áreas de arenitos fluviais e eólicos. Os Argissolos são solos que possuem um acréscimo substancial de argila no horizonte B se comparado ao horizonte A.

Os Neossolos são solos rasos ou profundos com formação bastante recente, não apresentando horizonte B. São encontrados nas mais diversas condições do relevo e drenagem. Devido à sua pequena espessura, e por ocorrerem em regiões de relevo forte ondulado e íngreme e, geralmente, com afloramentos rochosos.

Os Planossolos tem como principal característica a perda de argila no horizonte superficial, fazendo com que haja mudança abrupta na textura entre horizontes. A ocorrência dessa formação pedológica se dá em áreas de relevo plano ou suavemente ondulado, assim como o contato com drenagens em curtos ou longos períodos são característicos dos Planossolos. No caso de São Vicente estão junto as várzeas do Rio Ibicuí e Rio Jaguari.

\section{Uso e ocupação do solo}

As classes estabelecidas foram: lavouras, campos, vegetação arbórea e corpos d'água. As lavouras ocupam grande parte do município $(39,45 \%)$ sendo que esta classe abrange os diferentes tipos de culturas existentes, com destaque a cultura do arroz, pois a ocorrência dessa classe se dá junto às drenagens. Os campos compõem uma vegetação predominantemente formada por gramíneas e vegetação de pequeno porte. Estão a associadas a vegetação do Bioma Pampa, atualmente descaracterizada assim como pastagens ligadas a atividade pecuarista no município de São Vicente do Sul, que são destaque na estrutura e participação econômica. Estas áreas distribuem-se sobre um relevo ondulado de colinas, onde os campos são geralmente mais limpos, correspondem a 46,7\% da área. A vegetação arbórea e arbustiva compreende toda vegetação de grande a médio porte, que compõem remanescentes do Bioma Mata Atlântica, as matas ciliares ou matas galeria que circundam as drenagens, como também as áreas de reflorestamento. Esta classe abrange 10,6\% do território 
XVII Simpósio Brasileiro

de Geografia Fisica Aplicada

I Congresso Nacional

de Geografia Física

\section{OS DESAFIOS DA GEOGRAFIA FÍSICA NA FRONTEIRA DO CONHECIMENTO \\ Instituto de Geociências - Unicamp \\ Campinas - SP \\ 28 de Junho à 02 de Julho de 2017}

municipal. Por fim, os corpos d'água compõem barramentos e açudes presentes no município ocupando menos de 3\% do território. Estes açudes são utilizados para atividades de irrigação.

\section{Mapeamento Geoambiental}

Através da inter-relação dos parâmetros, definiu-se quatro sistemas geoambientais da área de estudo (figura III): Sistema São Vicente, Sistema das Colinas em arenito, Sistema dos morros e morrotes isolados e Sistema das áreas planas do Jaguari e Ibicuí. Tais sistemas apresentam restrições e aptidões ambientais.

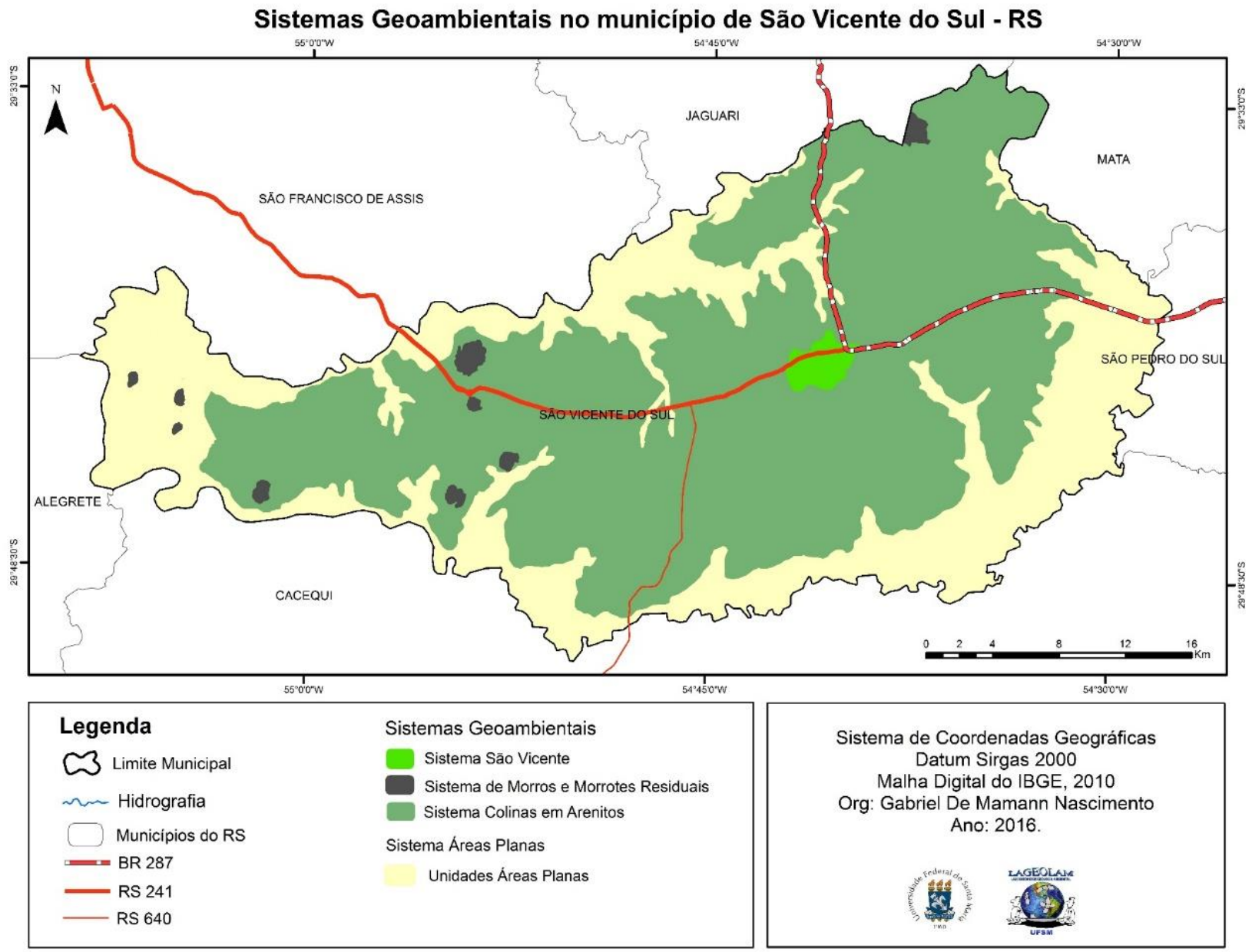

Figura 3: Sistemas Geoambientais de São Vicente do Sul - RS

O Sistema São Vicente corresponde a área urbana de São Vicente do Sul, que se caracteriza pela densidade demográfica mais elevada, e com elementos típicos da organização espacial urbana. A unidade encontram-se a maior parte do setor comercial, serviços em geral. A ação antrópica aqui é mais impactante perante a vegetação, rede de drenagens e tem-se a mata ciliar degradada em função da ocorrência no espaço urbano.

O Sistema Áreas Planas apresenta declives inferiores a 5\% e altitudes menores que 100 metros. Predominam os depósitos recentes associados ao canal principal do Jaguari e Ibicuí. Os são do tipo 
planossolos, gleissolos e neossolos ocorrendo junto às planícies de inundação dos rios, e são determinantes na diferenciação das unidades do sistema. Predomina processos de acumulação e deposição de sedimentos. Em porções do curso dos rios são formados bancos de areia e ilhas fluviais. Quanto ao uso, predominam os campos que permitem o desenvolvimento da pecuária e atividades agrícolas, com destaque para o cultivo de arroz, assim como há ocorrência de matas ciliares em estado de desgaste significativo.

O Sistema Colinas em arenitos correspondem às porções de relevo ondulado, na parte central, onde predominam declividades entre 5 e $15 \%$ e altitudes entre 100 e 200 metros. Quanto à geologia, apresentam os arenitos fluviais micáceos, com desenvolvimento de solos profundos e bem drenados. Em porções isoladas, as litologias são constituídas por arenitos com grânulos. Ocorrem processos erosivos, laminares e lineares junto às colinas, que podem desencadear o surgimento de ravinas. $\mathrm{O}$ controle destas erosões é fundamental para diminuir o assoreamento das drenagens. O uso caracterizase pelo predomínio de campos com criação de gado bovino e lavouras de soja. As matas ciliares encontram-se intensamente degradadas.

O Sistema de morros e morrotes isolados são as áreas íngremes, onde predominam declividades superiores a $15 \%$ e altitudes maiores que 200 metros. A geologia é constituída por arenitos médios com grânulos, que dão origem a solos rasos e afloramentos de rocha. Também associa-se o uso das áreas como vegetação arbórea, destacando Áreas de Preservação Permanente (APP) em topos de morros.

\section{Considerações Finais}

A análise permitiu a compartimentação da área em sistemas ambientais, tendo como objetivo alcançado a individualização de unidades com características homogêneas, obtendo restrições e aptidões definidas através da elaboração da pesquisa. O trabalho integra projetos amplos de mapeamento geoambiental do oeste do Rio Grande do Sul, que são de fundamental importância para a realização de planejamento e ordenamento territorial, atrelado ao meio físico e suas variadas formas de uso e ocupação.

\section{Bibliografia}

FIORI, A. P. Metodologias de Cartografia Geoambiental. In: Simpósio Brasileiro de Cartografia Geotécnica e Ambiental, São Carlos, Anais..., 2004. 
HASENACK, H.; WEBER, E. Base cartográfica vetorial continua do Rio Grande do Sul. Série Geoprocessamento. Centro de Ecologia/UFRGS: Porto Alegre, 2010. 1 DVD.

INSTITUTO DE PESQUISAS TECNOLÓGICAS. IPT. Mapeamento Geomorfológico do Estado de São Paulo. São Paulo. Escala 1:500.000, v. 2, 1981. 130 p.

SERVIÇO GEOLÓGICO DO BRASIL - CPRM. Programa Levantamentos Geológicos do Brasil. Brasília: CPRM, 2006.

STRAHLER, A. N. Hypsometric- analysis of erosion al topography. Geological Society of America Bulletin, v.63, n.10, p.1117-1142, 1952.

TRENTIN, R.; ROBAINA, L. E. S.; Metodologia para Mapeamento Geoambiental no Oeste do Rio Grande do Sul. In: XI Congresso Brasileiro de Geografia Física Aplicada, São Paulo, Anais... p. 3606$3615,2005$.

USGS - UNITED STATES GEOLOGICAL SURVEY. Aquisição de imagens orbitais digitais gratuitas dos satélites Landsat-5 e Landsat-8, 2016. Disponível em <http://earthexplorer.usgs.gov/>. Acesso em: 4. Maio. 2016. 